\title{
A rare cause for superior vena cava obstruction
}

\author{
Stevan C Wing, ${ }^{1}$ William M Ricketts, ${ }^{2}$ Rajesh B Banka, ${ }^{3}$ Zoltan Nagy, ${ }^{4}$ Stephen Ellis ${ }^{5}$ \\ ${ }^{1}$ Department of Respiratory Medicine, Homerton University Hospital, London, UK \\ 2Department of Respiratory Medicine, Newham University Hospital, London, UK \\ ${ }^{3}$ Department of Respiratory Medicine, King George Hospital, Essex, UK \\ ${ }^{4}$ Department of Radiology, King George Hospital, Essex, UK \\ ${ }^{5}$ Barts and The London, London, UK
}

Correspondence to Dr Stevan Christopher Wing, stevan.wing@nhs.net

\section{DESCRIPTION}

An 81-year-old gentleman was urgently referred to clinic with a 2 -week history of swelling of his face and arms (figure 1). He was not breathless and no other symptoms were elicited on history taking. He was previously well with the exception of osteoarthritis for which he took paracetamol only. He had smoked roll-up cigarettes for many years using up to $100 \mathrm{~g}$ of tobacco per week. There was no history of asbestos exposure.

Physical examination was consistent with superior vena cava obstruction (SVCO) with a fixed raised internal jugular vein, swollen face, arms and prominent superficial veins throughout his chest wall. He was not clubbed and had no palpable lymphadenopathy. He was sent for a chest radiograph (CXR) (figure 2). A clinical diagnosis of SVCO was made and a CT scan of the neck and thorax was arranged.

The CXR (figure 2) showed an apparent widening of the superior mediastinum due to unfolding of the aorta. No soft tissue lesion was seen in the paratracheal region and the SVC contour appeared normal.

Figure 3 shows an axial CT image from a postintravenous contrast scan and demonstrates the presence of abnormal anterior mediastinal soft tissue (white arrows). The SVC is of increased calibre and obstructed by a filling defect (black arrow). The tumour tissue in the anterior

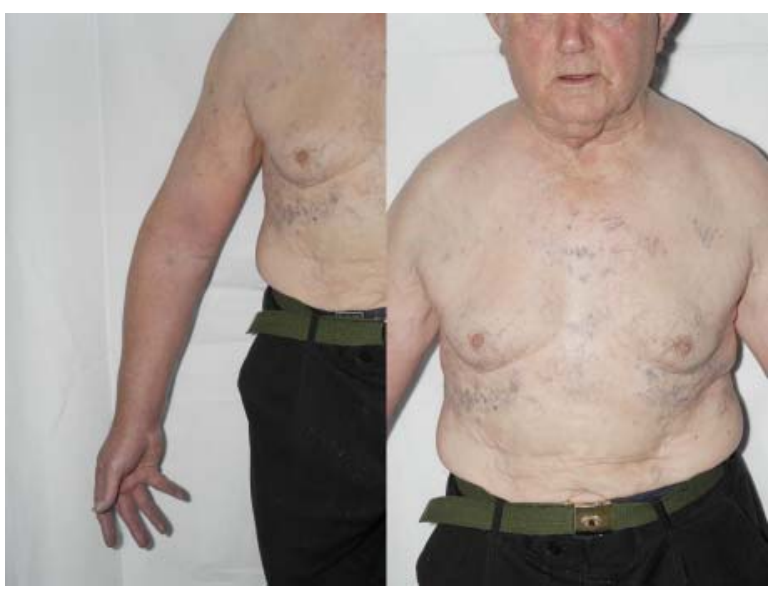

Figure 1 Photograph of the patient demonstrating arm swelling and extensive chest wall collateral vessels. mediastinum was thought not to contribute to the mediastinal silhouette on his CXR (figure 2).

Figure 4 is an oblique saggital CT image demonstrating a filling defect contiguous with that in the SVC extending via a tributary to the anterior medastinal soft tissue (black arrows).

The case was discussed in a multidisciplinary meeting and the patient went on to have an open mediastinal biopsy to confirm the diagnosis. This was performed through a minithoracotomy and demonstrated a type B2 thymoma on histological examination. His symptoms resolved with anticoagulation; however, he was considered too frail for any further intervention.

\section{DISCUSSION}

Tumour as the cause of SVCO is well recognised in primary lung cancer and lymphoma. Rarer tumour types causing SVCO are also frequently described in case series, although in the majority of cases external compression is the cause. Direct tumour invasion into the SVC is far more rare. ${ }^{1}$

Thymomas, although rare, are the most common tumours of the anterior mediastinum with an incidence of $0.15 / 100000 .^{2}$ As many as $34 \%$ invade through their own capsule but lymphogenous and haematogenous

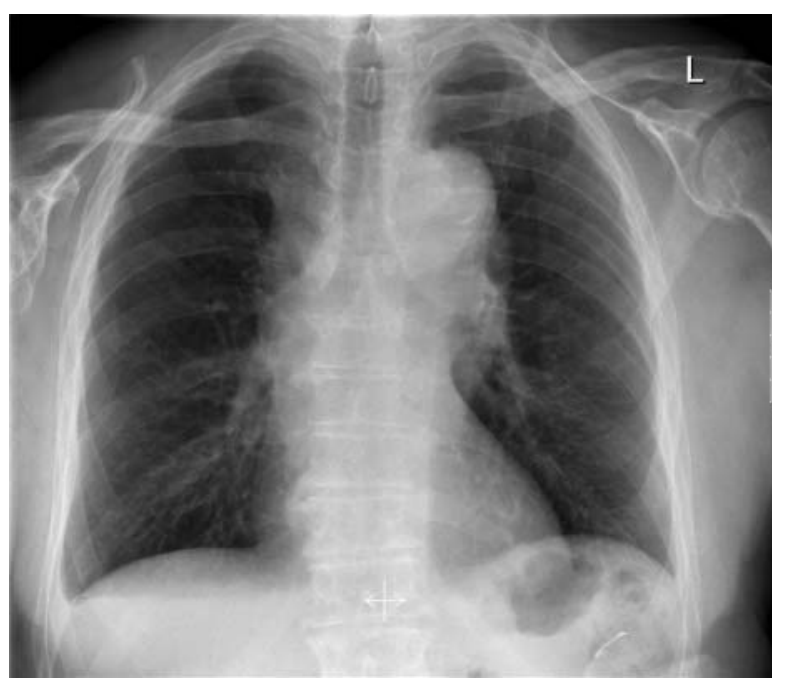

Figure 2 Chest radiograph. 


\section{BMJ Case Reports}

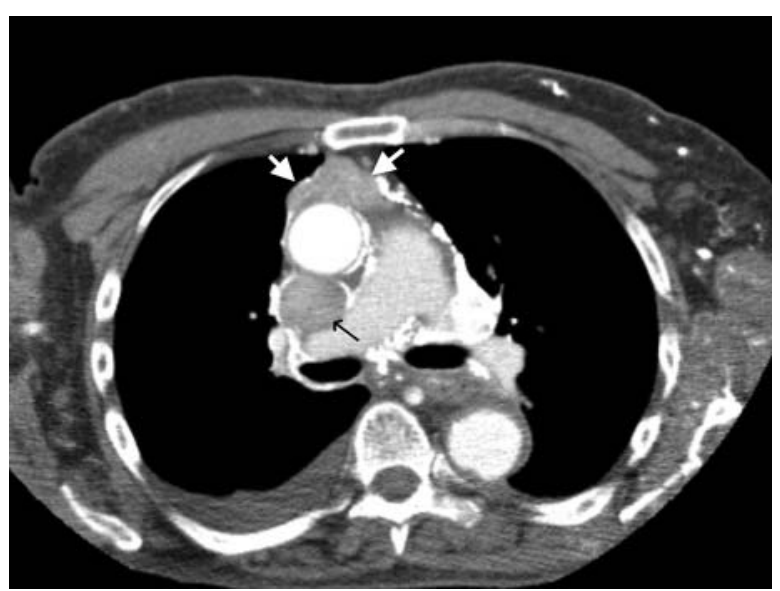

Figure 3 CT slice demonstrating a large thrombus in the superior vena cava (black arrows) anterior mediastinal soft tissue mass (white arrows) and venous collaterals.

spread are unusual. ${ }^{2}$ Management and prognosis are dependent on stage and the Masaoka clinical staging system is the most often used. ${ }^{2}$ Treatment may involve surgical resection or debulking with or without adjuvant radiotherapy; chemotherapy may be given in adjuvant or neoadjuvant regimes. ${ }^{3}$ Five-year survival ranges between $96 \%$ and $100 \%$ for stage 1 disease and $11-50 \%$ for stage $4 a^{2}$

In those who present with clinical SVCO crosssectional imaging is almost always requested to ascertain the nature of its cause. Causes include an obstructing mass (which may or may not be identifiable on CXR) stenosis of the SVC and, as in this case, tumour thrombus. Tumour thrombus is an important differential to consider since anticoagulation may be of therapeutic benefit. An SVC venogram with contrast injection via both arms will delineate any thrombus; injection via one arm introduces an artifactual filling defect in the SVC due to mixing of contrast enhanced flow with uncontrasted blood from the contralateral arm. Post-intravenous contrast CT, again ideally with contrast injection via both arms, provides more information regarding the possible causes of SVCO than a non-enhanced scan or a scan with contrast injected unilaterally. We suggest that, in cases of clinical SVCO, clinicians should consider the diagnosis of tumour thrombus and, if there is a suspicion, should request a postintravenous contrast CT scan with contrast injection via both arms. If diagnosed, the symptoms of SVCO may improve with anticoagulation which is

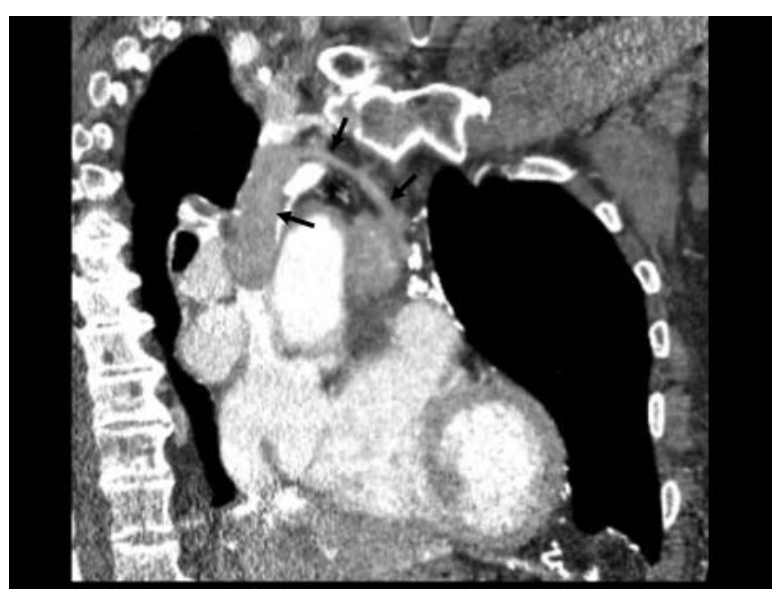

Figure 4 Multiplanar CT showing thrombosed mediastinal vein leading from the tumour to the superior vena cava.

particularly important for those who are unlikely to be offered any surgical or oncological intervention.

Learning Points

- Cross sectional imaging is mandatory when presented with cases of clinical superior vena cava obstruction (SVCO).

- Be aware of thymoma as a potential diagnosis in such cases.

- Consider tumour thrombus as a cause of SVCO; symptoms may improve with anticoagulation.

- ACT venogram with contrast injection via both arms simultaneously provides more information regarding the potential cause of SVCO.

Competing interests None.

Patient consent Obtained.

\section{REFERENCES}

1. Mathur A, Airan B, Bhan A, et al. Non-myxomatous cardiac tumours: twenty year experience. Indian Heart J 2000;52:319-23.

2. Duwe BV, Sterman DH, Musani Al. Tumors of the mediastinum. Chest 2005;128:2893-909.

3. Girard N, Mornex F, Van Houtte P, et al. Thymoma: a focus on current therapeutic management. J Thorac Oncol 2009;4:119-26. 


\section{BMJ Case Reports}

This pdf has been created automatically from the final edited text and images.

Copyright 2012 BMJ Publishing Group. All rights reserved. For permission to reuse any of this content visit http://group.bmj.com/group/rights-licensing/permissions.

BMJ Case Report Fellows may re-use this article for personal use and teaching without any further permission.

Please cite this article as follows (you will need to access the article online to obtain the date of publication).

Wing SC, Ricketts WM, Banka RB, Nagy Z, Ellis S. A rare cause for superior vena cava obstruction. BMJ Case Reports 2012;10.1136/bcr-2012-006456, Published XXX

Become a Fellow of BMJ Case Reports today and you can:

- Submit as many cases as you like

- Enjoy fast sympathetic peer review and rapid publication of accepted articles

- Access all the published articles

- Re-use any of the published material for personal use and teaching without further permission

For information on Institutional Fellowships contact consortiasales@bmjgroup.com

Visit casereports.bmj.com for more articles like this and to become a Fellow 